\title{
SPOCK1 Overexpression Confers a Poor Prognosis in Urothelial Carcinoma
}

\author{
Li-Jung Ma1 ${ }^{1}$, Wen-Jen $\mathrm{Wu}^{2,3,4,5,6}$, Yu-Hui Wang7, Ting-Feng Wu ${ }^{8}$, Peir-In Liang ${ }^{9}$, I-Wei Chang10, Hong-Lin \\ $\mathrm{He}^{10}$, Chien-Feng $\mathrm{Li}^{1,8,11,12,13 凶}$ \\ 1. Department of Pathology, Chi-Mei Medical Center, Tainan, Taiwan; \\ 2. Graduate Institute of Medicine, College of Medicine, Kaohsiung Medical University, Kaohsiung, Taiwan; \\ 3. Department of Urology, School of Medicine, College of Medicine, Kaohsiung Medical University, Kaohsiung, Taiwan; \\ 4. Department of Urology, Kaohsiung Medical University Hospital, Kaohsiung, Taiwan; \\ 5. Department of Urology, Kaohsiung Municipal Hsiao-Kang Hospital, Kaohsiung, Taiwan; \\ 6. Center for Stem Cell Research, Kaohsiung Medical University, Kaohsiung, Taiwan; \\ 7. Institute of Bioinformatics and Biosignal Transduction, National Cheng Kung University, Tainan, Taiwan; \\ 8. Departments of Biotechnology, Southern Taiwan University of Science and Technology, Tainan, Taiwan; \\ 9. Department of Pathology, Kaohsiung Medical University Hospital, Kaohsiung Medical University, Kaohsiung, Taiwan; \\ 10. Department of Pathology, E-DA Hospital, I-Shou University, Kaohsiung, Taiwan; \\ 11. National Cancer Research Institute, National Health Research Institutes, Tainan, Taiwan; \\ 12. Department of Biotechnology, Southern Taiwan University of Science and Technology, Tainan, Taiwan; \\ 13. Institute of Clinical Medicine, Kaohsiung Medical University \& Department of Internal Medicine and Cancer Center, Kaohsiung Medical University Hos- \\ pital, Kaohsiung Medical University, Kaohsiung, Taiwan. \\ $\square$ Corresponding author: Chien-Feng Li, MD., PhD., Department of Pathology, Chi Mei Medical Center, 901 Chunghwa Road, Yung Kang Dist., Tainan County \\ 710, TAIWAN. Tel: +886-6-2812811 ext. 53680; E-mail: angelo.p@yahoo.com.tw.
}

( ) Ivyspring International Publisher. Reproduction is permitted for personal, noncommercial use, provided that the article is in whole, unmodified, and properly cited. See http://ivyspring.com/terms for terms and conditions.

Received: 2015.08.21; Accepted: 2015.12.04; Published: 2016.01.29

\begin{abstract}
Purpose: The majority deaths of cancer patients are related to metastasis, thus genes associated with cell motility interest us. SPOCKI was elected by data mining and serial evaluation. In addition, SPOCKI has been reported to be highly expressed in different human cancers and been related to adverse outcomes. Therefore, we validate its prognostic significance in urothelial carcinoma (UC).

Materials and Methods: Real-time RT-PCR assay was used to detect SPOCKI transcript level in 27 urinary tract urothelial carcinoma (UTUC) and 27 urinary bladder urothelial carcinoma (UBUC) samples. Immunohistochemistry evaluated by $\mathrm{H}$-score determined SPOCK 1 expressions in 340 UTUCs and 295 UBUCs. The transcript and protein expression were correlated with clinicopathological features. Further evaluations of the prognostic significance of SPOCK1 for disease-specific survival (DSS) and metastasis-free survival (MeFS) were analyzed.

Results: The expressions of SPOCK1 in UC were higher than those in normal urothelium by immunohistochemistry. The statistical analysis of clinicopathologic characteristics and immunohistochemistry showed that the higher expression of SPOCK 1 was correlated to PT status $(P<0.001)$, lymph node metastasis (UTUC, $P=0.006$; UBUC, $P=0.033$ ), higher histological grade (UTUC, $P<0.001$; UBUC, $P<0.001$ ), vascular invasion (UTUC, $P<0.001$; UBUC, $P<0.001$ ), perineurial invasion (UTUC, $P<0.001$; UBUC, $P=0.001$ ) and frequent mitosis (UTUC, $P<0.001$; UBUC, $P=0.001$ ). The prognosis of $S P O C K 1$ of UC showed high SPOCK1 expression had significantly worse DSS and MeFS.

Conclusions: The investigation demonstrated that the higher expression of SPOCK 1 correlates with a poor prognosis in UC.
\end{abstract}

Key words: transcriptome, SPOCK1, urothelial carcinoma, prognosis.

\section{Introduction}

Urothelial carcinoma (UC), the predominant type among the varied histologic malignancies arising from the urinary tract, derives from the urothelial lining either in the lower tract (urinary bladder) or the upper tract (renal pelvis, ureter) [1,2]. About $80 \%$ of patients with urinary bladder urothelial carcinoma 
face recurrence within one to two years of initial treatment $[3,4]$. A significant proportion of these patients die because of recurrence even after receiving standard treatment [5]. In addition, around $25 \%$ of patients with UC have muscle-invasive disease, and either present with or later develop metastasis [6]. Thus effort is needed to explore the development and progression of UC in order to identify a better prognosticator and to enable better oncology-targeted therapies.

The majority deaths among cancer patients result from metastasis rather than the primary disease. Metastasis is the distal settlement of tumor cells and stats escaping from the primary location. Therefore we investigated genes related to cell motility in UC, which have not been systemically evaluated before. From data mining and comparison with other related genes, SPOCK1 demonstrated exciting associations with invasiveness and metastasis in the transcriptome GSE31684.

SPOCK1 encodes a calcium-binding matricellular glycoprotein belonging to the SPARC family [7]. The importance of SPARC in regulating proliferation, cell-cycle progression, apoptosis, adhesion, and cell-matrix interaction has been well documented [8]. Recent evidence suggests that SPOCK1, which is structurally similar, may play a crucial role in invasion of pilocytic astrocytoma [9] and in progression of hepatocellular carcinoma (HCC) [10]. Our study has found that SPOCK1 expression is correlated with adverse clinicopathological factors and survival in a well-characterized cohort of UC.

\section{Materials and Methods}

\section{Data mining of the GEO to identify altered transcripts in UC}

One dataset, GSE31684 (http://www.ncbi.nlm. nih.gov/geo/query/acc.cgi?acc=GSE31684), which profiled radical cystectomy specimens from 93 urinary bladder urothelial carcinoma (UBUC) cases, was identified by data mining of the GEO (National Center for Biotechnology information, Bethesda, MD, USA) and by Affymetrix U133 Plus 2.0 Array. To evaluate the gene expression level, we imported the raw CEL files into the Nexus Expression 3 statistical software (BioDiscovery, EI Segundo, CA, USA). All probe sets were used in the evaluation without preselection or filtering. We performed supervised comparative analysis to examine the statistical significance of differentially expressed genes on the basis of progression in primary tumor status ( $\mathrm{pT}$ ) and the development of metastatic events. With this intention, we compared the differential expression in low-stage (pTa-pT1) UCs and muscle-invasive, high-stage
(pT2-pT4) UCs, and compared non-metastatic lesions to those that developed distal metastasis, respectively, in order to perform functional profiles focusing on the genes related to cell motility (GO:0048870). Only genes displaying significantly differential expression in both stage $(\log 2$ ratio $>1.0)$ and metastasis $(\log 2$ ratio $>0.5$ ) were enrolled for initial validation.

\section{Patients and tumor specimens}

This study was approved by the Institutional Review Board (IRB) of Chi Mei Medical Center, approval number IRB10302015. All specimens were obtained from the BioBank of Chi Mei Medical Center and had been collected previously following official ethical guidelines. We retrieved urothelial carcinoma cases for immunohistochemical study and survival analysis between 1996 and 2004 from the Chi Mei Medical Center archives. For the initial validation, which focused on identifying the most significant among the candidate genes, we randomly selected 50 UBUCs and 50 urinary tract urothelial carcinomas (UTUCs) as the pilot batch of cases. We further evaluated the gene demonstrating greatest clinical significance in an independent cohort, as previously described [11]. The independent cohort included a total of 635 consecutively treated, well-characterized cases: 340 tumors originating from the UT and 295 arising from the UB. All patients received nephroureterectomy and excision of the bladder with regional lymph node dissection. Of these cases, UBUC patients with pT3 or pT4 stage tumors or with nodal involvement received cisplatin-based post-operative adjuvant chemotherapy, but patients with renal insufficiency obtained carboplatin. However, only 29 of the 106 UTUC patients with pT3 or pT4 stage tumors or nodal involvement received post-operative adjuvant chemotherapy. In addition, neo-adjuvant chemotherapy was not introduced to the patients with UBUC or UTUC in our cohort. The criteria for clinicopathological evaluation were essentially identical to those in our previous work [11]. Two pathologists (P.I.L \& C.F.L) re-evaluated hematoxylin-eosin sections of all cases.

\section{Immunohistochemical staining}

Following histological review, tissue blocks containing the most invasive area of each case were selected for immunohistochemical study. We cut representative tissue sections of $4-\mu \mathrm{m}$ thickness onto precoated slides from the paraffin-embedded tissue blocks, succeeded by deparaffinization, rehydration, antigen retrieval, and blockage of endogenous peroxidase. Endogenous peroxidase was buffered with saline for 15 minutes and subsequently incubated with a primary antibody targeting CALD1 (1:100, 
C-19, Santa Cruz) or SPOCK1 (1:200, 102D1, Santa Cruz) for one hour. We detected primary antibodies using the DAKO ChemMate EnVision Kit (K5001, Carpinteria, CA, USA). The presence of brown chromogen in the cytoplasm of target cells indicated positive immunoreactivity. The quality of immunostaining was ensured by a negative control incubated without the primary antibody.

\section{Interpretation and scoring of immunohisto- chemistry}

Two pathologists (P.I.L \& C.F.L) appraised the immunohistochemistry without prior knowledge of clinical and follow-up data. Immunoreactivity was estimated with a combination of the percentage and intensity of positively stained tumor cytoplasm in order to generate the $\mathrm{H}$-score, which was calculated by the following equation: $\mathrm{H}$-score $=\sum \mathrm{Pi}(\mathrm{i}+1)$, where $\mathrm{i}$ is the intensity of stained tumor cells $(0$ to $3+)$, and $\mathrm{Pi}$ is the percentage of stained tumor cells for each intensity varying from $0 \%$ to $100 \%$. This formula produces a score range from 100-400, where 100 equals $100 \%$ of tumor cells showing negative results and 400 equals $100 \%$ of tumor cells strongly stained $(3+)[12$, 13].

\section{Real-time RT-PCR}

Since SPOCK1 was identified as the most significantly altered gene, its transcript level was further determined in a collection of snap-frozen samples containing high percentage (no less than $70 \%$ ) of tumor elements consisting of 27 UBUCs and 27 UTUCs, respectively. For this goal, total RNAs were extracted, quantified, and submitted for reverse-transcription. Using pre-designed TaqMan assay reagents (Applied Biosystems), we measured mRNA abundance of SPOCK1 (Hs00270274_m1) with the ABI StepOnePlus ${ }^{\mathrm{TM}}$ System. The fold expression of SPOCK1 relative to normal urothelium was calculated by comparative $\mathrm{Ct}$ method, after normalization to POLR2A (Hs01108291_m1) as the internal control.

\section{Statistical analysis}

Statistical analysis was performed using SPSS V.14.0 software (SPSS Inc. Chicago, IL, USA). The median H-score of immunohistochemistry for SPOCK1 was the cutoff to dichotomize the study cohort, separating cases into high expression and low expression groups. We employed the chi-square test to compare SPOCK1 expression status and various clinicopathological parameters. The end points analyzed were disease-specific survival (DSS) and metastasis-free survival (MeFS), calculated from the date of curative surgery to the date an event developed. Patients lost to follow-up were censored on the final follow-up date. We plotted survival curves using the Kaplan-Meier method, and evaluated prognostic differences between groups using the log-rank test. Parameters demonstrating $P$ values less than 0.05 in univariate analysis were subsequently enrolled into multivariate tests using the Cox proportional hazards model. For all analyses, two-sided tests of significance with $P<0.05$ were considered significant.

\section{Results}

\section{CALDI, SPOCKI, SCG2, IGFI and CEECAMI were identified as significant differentially up- regulated transcripts implicated in cell motil- ity in UC}

From the transcriptomic profiles of GSE31684, we found 109 probes covering 52 transcripts associated with cell motility (GO:0048870). Of these, only seven probes covering five genes showed significant differential expression associated with both increments of primary tumor stage and the presence of distal metastasis (Fig. 1 and Table 1). Of these, the upregulated CALD1 and SPOCK1 were more significant and met the selection criteria. Of the candidate genes, CALD1 was the most significantly upregulated with increments of primary tumor status, showing a $\log 2$ ratio of 1.6569 fold. SPOCK1 upregulation was most significantly associated with the presence of distal metastasis ( $\log 2$ ratio of 0.843 ).

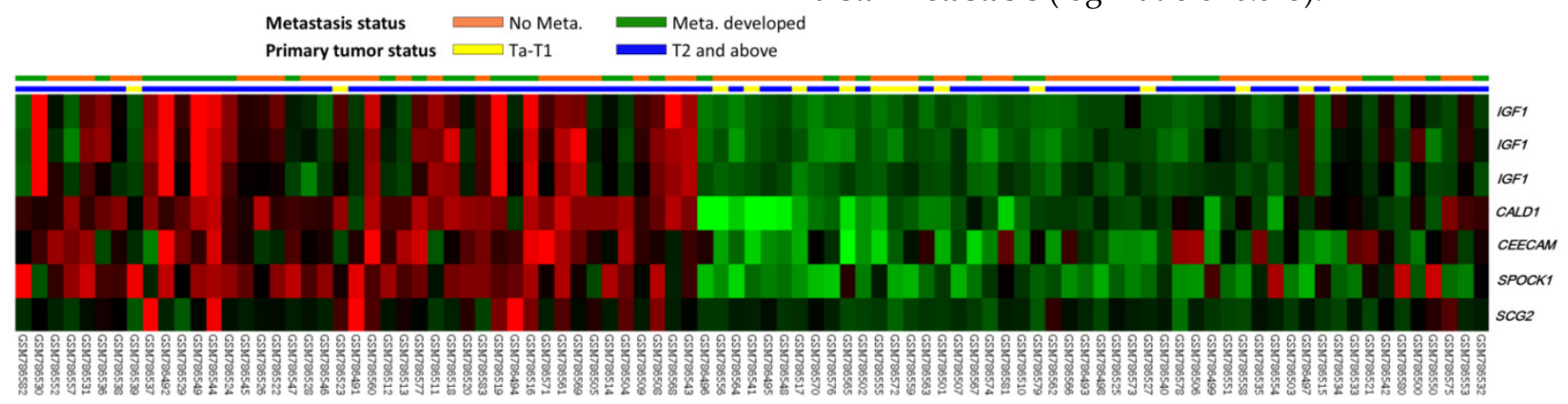

Figure 1. Analysis of gene expression in urothelial carcinomas of the bladders from a published transcriptomic dataset (GSE31684). Clustering analysis of genes focusing on cell motility (GO:0048870) showed upregulation of IGFI, CALDI, CEECAM, SPOCKI and SCG2 were more significantly associated with both higher primary tumor status (PT) and distal metastasis. Specimens from high PT (blue lines) and low PT (yellow lines) are indicated on top of the heatmap, and upregulation and downregulation of genes are illustrated as a spectrum of brightness of red and green, respectively, with those unaltered coded as black. 
Table 1. Summary of differentially expressed genes associated with Cell Motility (GO: 0048870) and showed positive associations to cancer invasiveness and metastasis in the transcriptome of urothelial carcinoma of urinary bladder (GSE31684).

\begin{tabular}{|c|c|c|c|c|c|c|c|}
\hline \multirow[t]{2}{*}{ Probe } & \multicolumn{2}{|c|}{$\begin{array}{l}\text { Comparing } \mathrm{T} 2-4 \text { to } \\
\text { Ta-T1 }\end{array}$} & \multicolumn{2}{|c|}{$\begin{array}{l}\text { Comparing Meta. } \\
\text { to Non-Meta.\# }\end{array}$} & \multirow[t]{2}{*}{$\begin{array}{l}\text { Gene } \\
\text { Symbol }\end{array}$} & \multirow[t]{2}{*}{ Biological Process } & \multirow[t]{2}{*}{ Molecular Function } \\
\hline & $\log$ ratio & p-value & $\log$ ratio & p-value & & & \\
\hline 201617_x_at & 1.6569 & $<0.0001$ & 0.6623 & 0.0085 & CALD1 & cell motility, muscle contraction & $\begin{array}{l}\text { actin binding, calmodulin binding, } \\
\text { myosin binding, tropomyosin } \\
\text { binding }\end{array}$ \\
\hline 202363_at & 1.1471 & 0.0003 & 0.843 & 0.0005 & SPOCK1 & $\begin{array}{l}\text { cell adhesion, cell motility, cell proliferation, multicel- } \\
\text { lular organismal development, nervous system devel- } \\
\text { opment }\end{array}$ & calcium ion binding \\
\hline 204035_at & 0.5489 & 0.0071 & 0.519 & 0.0009 & SCG2 & $\begin{array}{l}\text { MAPKKK cascade, angiogenesis, cell motility, endothe- } \\
\text { lial cell migration, eosinophil chemotaxis, induction of } \\
\text { positive chemotaxis, inflammatory response, intracel- } \\
\text { lular signaling cascade, negative regulation of apopto- } \\
\text { sis, negative regulation of endothelial cell proliferation, } \\
\text { positive regulation of endothelial cell proliferation, } \\
\text { protein secretion }\end{array}$ & $\begin{array}{l}\text { calcium ion binding, chemoat- } \\
\text { tractant activity, cytokine activity }\end{array}$ \\
\hline 209540_at & 0.7559 & 0.0038 & 0.6879 & 0.0005 & IGF1 & $\begin{array}{l}\text { DNA replication, Ras protein signal transduction, cell } \\
\text { motility, glycolate metabolic process, muscle develop- } \\
\text { ment, positive regulation of cell proliferation, regulation } \\
\text { of steroid hormone receptor signaling pathway, sensory } \\
\text { perception of sound, signal transduction, skeletal de- } \\
\text { velopment }\end{array}$ & $\begin{array}{l}\text { growth factor activity, hormone } \\
\text { activity, insulin-like growth factor } \\
\text { receptor binding, prothoracico- } \\
\text { trophic hormone activity }\end{array}$ \\
\hline 209541_at & 0.8353 & 0.0015 & 0.7105 & 0.0005 & IGF1 & $\begin{array}{l}\text { DNA replication, Ras protein signal transduction, cell } \\
\text { motility, glycolate metabolic process, muscle develop- } \\
\text { ment, positive regulation of cell proliferation, regulation } \\
\text { of steroid hormone receptor signaling pathway, sensory } \\
\text { perception of sound, signal transduction, skeletal de- } \\
\text { velopment }\end{array}$ & $\begin{array}{l}\text { growth factor activity, hormone } \\
\text { activity, insulin-like growth factor } \\
\text { receptor binding, prothoracico- } \\
\text { trophic hormone activity }\end{array}$ \\
\hline 209542_x_at & 0.3483 & 0.0058 & 0.3631 & 0.0001 & IGF1 & $\begin{array}{l}\text { DNA replication, Ras protein signal transduction, cell } \\
\text { motility, glycolate metabolic process, muscle develop- } \\
\text { ment, positive regulation of cell proliferation, regulation } \\
\text { of steroid hormone receptor signaling pathway, sensory } \\
\text { perception of sound, signal transduction, skeletal de- } \\
\text { velopment }\end{array}$ & $\begin{array}{l}\text { growth factor activity, hormone } \\
\text { activity, insulin-like growth factor } \\
\text { receptor binding, prothoracico- } \\
\text { trophic hormone activity }\end{array}$ \\
\hline 224794_s_at & 1.0792 & $<0.0001$ & 0.4795 & 0.0067 & $\begin{array}{l}\text { CEECAM } \\
1\end{array}$ & $\begin{array}{l}\text { cell adhesion, cell motility, leukocyte adhesion, lipo- } \\
\text { polysaccharide biosynthetic process }\end{array}$ & $\begin{array}{l}\text { oxidoreductase activity; acting on } \\
\text { single donors with incorporation of } \\
\text { molecular oxygen; incorporation of } \\
\text { two atoms of oxygen, procolla- } \\
\text { gen-lysine 5-dioxygenase activity }\end{array}$ \\
\hline
\end{tabular}

\#, Meta., distal metastasis developed during follow-up; Non-Meta.: no metastatic event developed.

\section{SPOCK1 expression was most significantly associated with tumor aggressiveness in genes associated with cell motility}

In the pilot batch of cases for initial validation, SPOCK1 but not CALD1 overexpression was significantly associated with both primary tumor status (UTUC, $P=0.004$; UBUC, $P=0.009$ ) and nodal metastasis (UTUC, $P=0.037$; UBUC, $P=0.042$ ) (Table S1). Moreover, SPOCK1 was the most significant candidate that predicted inferior DSS (UTUC, $P=0.0002$; UBUC, $P=0.0017$ ) and worse MeFS (UTUC, $P<0.0001$; UBUC, $P=0.0006$ ) (Table S2).

\section{SPOCKI mRNA expression is positively asso- ciated with higher PT status in both UTUC and UBUC}

In the 27 UTUCs and 27 UBUCs tested, SPOCK1 mRNA expression was significantly upregulated with higher pT status in both UTUC $(P=0.002)$ and UBUC $(P=0.001)$, suggesting that it plays a role in tumor progression (Fig. 2).

\section{Clinicopathological findings for UTUC}

The clinicopathological features of the UTUC patients are listed in Table 2. The disease showed no predilection for either sex. The median age at diagnosis was 68 years, ranging from 34 to 87 years. Sixty-two patients $(18.2 \%)$ suffered from multifocal tumors, and 49 (14.4\%) had tumors involving both the renal pelvis and ureter. The majority of cases $(n=284$, $83.5 \%$ ) were of high histological grade. Advanced pT stage (pT2-T4) was seen in 159 cases (46.8\%). Around one-half of the cases $(n=167,49.1 \%)$ showed mitotic activity. Vascular invasion and perineurial invasion were noted in 106 cases (31.2\%) and 19 cases (5.9\%), respectively. Nodal metastasis was observed in 28 patients $(8.2 \%)$.

\section{Clinicopathological findings for UBUC}

UBUC patients were predominantly male $(n=216,73.2 \%)$ and older than 65 years $(n=174,59.0 \%)$. As outlined in Table 2, most $(n=239,81 \%)$ were of high histological grade, with $123(41.7 \%)$ in advanced 
stages (pT2-T4) at initial diagnosis. One hundred and fifty-six cases (52.9\%) showed high mitotic activity ( $\geq$ $10 / 10 \mathrm{HPFs}$ ). Lymph node metastasis was detected in $23.6 \%$ of patients $(n=29)$. Vascular invasion was evident in 49 cases $(16.6 \%)$ and perineurial invasion in 20 cases $(6.8 \%)$.

\section{Correlation of SPOCK1 immunoreactivity with parameters in UTUC and UBUC}

SPOCK1 demonstrates variable cytoplasmic expression in carcinoma cells of both the UT and UB, with median H-scores of 260 (range, 110-380) and 285 (range, 115-375) respectively. In contrast, the expression level of SPOCK1 is very low in normal urothe-

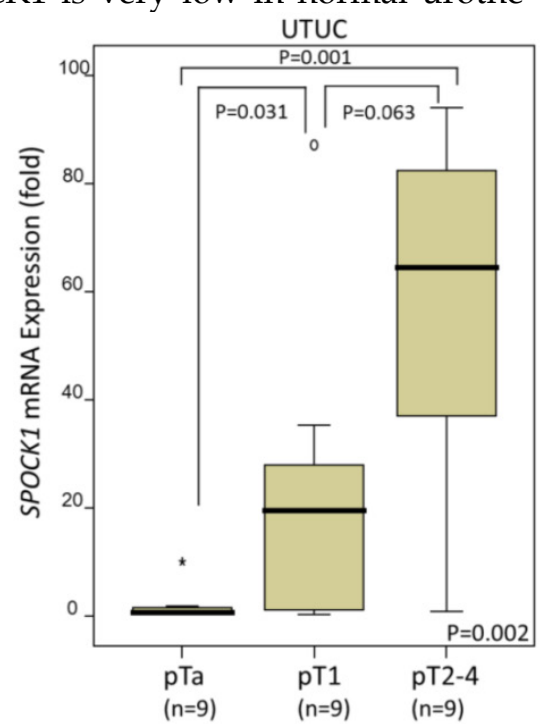

lium, with H-scores ranging from 100 to 140 . After dichotomizing the tumors into those with low and high SPOCK1 expression, as illustrated in Table 2, we found increased SPOCK1 expression was significantly associated with increments of pT status $(P<0.001)$, lymph node metastasis (UTUC, $P=0.006$; UBUC, $P=0.033$ ), higher histological grade (UTUC, $P<0.001$; UBUC, $P<0.001$ ), vascular invasion (UTUC, $P<0.001$; UBUC, $P<0.001$ ), perineurial invasion (UTUC, $P<0.001$; UBUC, $P=0.001)$ and frequent mitosis (UTUC, $P<0.001$; UBUC, $P=0.001$ ) in urothelial carcinomas of the two locations. These findings point to a role for SPOCK1 in the progression of UC.

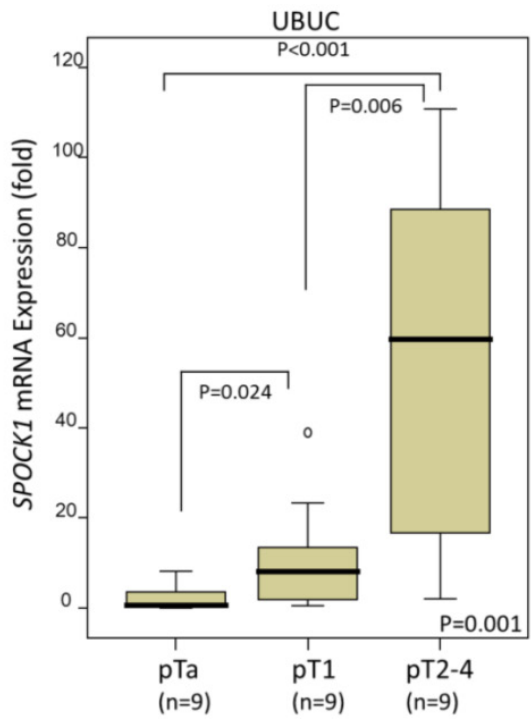

Figure 2. Quantitative real-time RT-PCR analysis revealed that SPOCKI mRNA expression was significantly upregulated in urinary tract urothelial carcinomas (UTUCs, left panel) and urinary bladder urothelial carcinomas (UBUCs, right panel) with higher primary tumor status.

Table 2. Correlations between SPOCK1 Expression and other important clinicopathological parameters in urothelial carcinomas.

\begin{tabular}{|c|c|c|c|c|c|c|c|c|c|}
\hline \multirow[t]{3}{*}{ Parameter } & \multirow[t]{3}{*}{ Category } & \multicolumn{4}{|c|}{ Upper Urinary Tract Urothelial Carcinoma } & \multicolumn{4}{|c|}{ Urinary Bladder Urothelial Carcinoma } \\
\hline & & \multirow{2}{*}{$\begin{array}{l}\text { Case } \\
\text { No. }\end{array}$} & \multicolumn{2}{|c|}{ SPOCK1 Expression } & \multirow[t]{2}{*}{$P$ value } & \multirow{2}{*}{$\begin{array}{l}\text { Case } \\
\text { No. }\end{array}$} & \multicolumn{2}{|c|}{ SPOCK1 Expression } & \multirow[t]{2}{*}{$P$ value } \\
\hline & & & Low & High & & & Low & High & \\
\hline \multirow[t]{2}{*}{ Gender\& } & Male & 158 & 82 & 76 & 0.514 & 216 & 105 & 111 & 0.489 \\
\hline & Female & 182 & 88 & 94 & & 79 & 42 & 37 & \\
\hline Age (years)\# & & 340 & $65.16 \pm 10.91$ & $66.00 \pm 8.76$ & 0.961 & 295 & $65.27 \pm 13.02$ & $66.81 \pm 11.35$ & 0.543 \\
\hline \multirow[t]{3}{*}{ Tumor location\& } & Renal pelvis & 141 & 66 & 75 & 0.194 & - & - & - & - \\
\hline & Ureter & 150 & 83 & 67 & & - & - & - & - \\
\hline & Renal pelvis \& ureter & 49 & 21 & 28 & & - & - & - & - \\
\hline \multirow[t]{2}{*}{ Multifocality\& } & Single & 278 & 143 & 135 & 0.261 & - & - & - & - \\
\hline & Multifocal & 62 & 27 & 35 & & - & - & - & - \\
\hline \multirow[t]{3}{*}{ Primary tumor $(\mathrm{T})$ \& } & $\mathrm{Ta}$ & 89 & 61 & 28 & $<0.001^{*}$ & 84 & 70 & 14 & $<0.001^{*}$ \\
\hline & $\mathrm{T} 1$ & 92 & 57 & 35 & & 88 & 42 & 46 & \\
\hline & $\mathrm{T} 2-\mathrm{T} 4$ & 159 & 52 & 107 & & 123 & 35 & 88 & \\
\hline \multirow[t]{2}{*}{ Nodal metastasis\& } & Negative (N0) & 312 & 163 & 149 & $0.006^{*}$ & 266 & 138 & 128 & $0.033^{*}$ \\
\hline & Positive (N1-N2) & 28 & 7 & 21 & & 29 & 9 & 20 & \\
\hline \multirow{2}{*}{ Histological grade \& } & Low grade & 56 & 41 & 15 & $<0.001^{*}$ & 56 & 46 & 10 & $<0.001^{*}$ \\
\hline & High grade & 284 & 129 & 155 & & 239 & 101 & 138 & \\
\hline \multirow[t]{2}{*}{ Vascular invasion\& } & Absent & 234 & 148 & 86 & $<0.001^{*}$ & 246 & 140 & 106 & $<0.001^{*}$ \\
\hline & Present & 106 & 22 & 84 & & 49 & 7 & 42 & \\
\hline \multirow[t]{2}{*}{ Perineural invasion\& } & Absent & 321 & 169 & 152 & $<0.001^{*}$ & 275 & 144 & 131 & $0.001^{*}$ \\
\hline & Present & 19 & 1 & 18 & & 20 & 3 & 17 & \\
\hline $\begin{array}{l}\text { Mitotic rate (per } 10 \\
\text { high power fields)\# }\end{array}$ & & 340 & $10.63 \pm 12.07$ & $13.99 \pm 12.30$ & $<0.001^{*}$ & 295 & $12.41 \pm 13.89$ & $16.39 \pm 13.95$ & $0.001^{*}$ \\
\hline
\end{tabular}




\section{Survival analysis for UTUC}

Follow-up information, with duration ranging from 1 to 176 months (median, 38), was available for all patients. Univariate and multivariate analyses of the association between clinical outcomes and various clinicopathological features of UTUC cases are summarized in Table 3. Both univariate and multivariate analysis revealed that poor DSS was significantly associated with multifocality $(P=0.0042$ and $P=0.006$, respectively), advanced pT $(P<0.0001$ and $P=0.010$, respectively), lymph node metastasis $(P<0.0001$ and $P<0.0001$, respectively), high histological grade ( $P=0.0171$ and $P=0.044$, respectively), perineurial invasion $(P<0.0001$ and $P=0.002$, respectively), and high SPOCK1 expression $(P<0.0001$ and $P=0.031$, respectively). Similar results were also seen for MeFS, excluding primary tumor and histological grade. However, vascular invasion in UTUC was also independently and significantly associated with worse MeFS $(P<0.0001$ and $P=0.015$, respectively).

\section{Survival analysis for UBUC}

Follow-up information is available for all patients, with a median duration of 23.1 months (range, 1-109). As illustrated in Table 4, in multivariate analyses, pT stage, mitotic rate, and SPOCK1 expression were significantly associated with both inferior DSS $(P<0.001, \quad P=0.015$ and $P<0.001$, respectively) and MeFS $(P=0.008, P=0.009$ and $P<0.001$, respectively). Perineurial invasion was also predictive of DSS.

\section{Prognostic significance of SPOCK 1 expression in UC}

In the univariate analyses (Table 3 ), patients with UTUC showing high SPOCK1 expression had significantly worse DSS $(P<0.0001$, Fig. 4 A) and MeFS $(P<0.0001$, Fig. 4B). Similar results were also noted for patients with UBUC (Table 4, Fig. 4C, and Fig. 4D). Of regard, SPOCK1 overexpression remained an independent prognosticator portending poor DSS and MeFS for both UTUC and UBUC patients (Table 3 and Table 4).

Table 3. Univariate log-rank and multivariate analyses for Disease-specific and Metastasis-free Survivals in Upper urinary tract urothelial carcinoma

\begin{tabular}{|c|c|c|c|c|c|c|c|c|c|c|c|c|}
\hline \multirow[t]{3}{*}{ Parameter } & \multirow[t]{3}{*}{ Category } & \multirow{3}{*}{$\begin{array}{l}\text { Case } \\
\text { No. }\end{array}$} & \multicolumn{5}{|c|}{ Disease-specific Survival } & \multicolumn{5}{|c|}{ Metastasis-free Survival } \\
\hline & & & \multicolumn{2}{|c|}{ Univariate analysis } & \multicolumn{3}{|c|}{ Multivariate analysis } & \multicolumn{2}{|c|}{ Univariate analysis } & \multicolumn{3}{|c|}{ Multivariate analysis } \\
\hline & & & No. of event & $P$ value & R.R. & 95\% C.I. & $P$ value & No. of event & $P$ value & R.R. & 95\% C.I. & $P$ value \\
\hline \multirow[t]{2}{*}{ Gender } & Male & 158 & 28 & 0.9301 & - & - & - & 32 & 0.7904 & - & - & - \\
\hline & Female & 182 & 33 & & - & - & - & 38 & & - & - & - \\
\hline \multirow[t]{2}{*}{ Age (years) } & $<65$ & 138 & 26 & 0.8660 & - & - & - & 30 & 0.8470 & - & - & - \\
\hline & $\geq 65$ & 202 & 35 & & - & - & - & 40 & & - & - & - \\
\hline \multirow[t]{3}{*}{ Tumor side } & Right & 177 & 34 & 0.7188 & - & - & - & 38 & 0.3074 & - & - & - \\
\hline & Left & 154 & 26 & & - & - & - & 32 & & - & - & - \\
\hline & Bilateral & 9 & 1 & & - & - & - & 0 & & - & - & - \\
\hline \multirow[t]{3}{*}{ Tumor location } & Renal pelvis & 141 & 24 & $0.0120^{*}$ & 1 & - & 0.912 & 31 & 0.0659 & - & - & - \\
\hline & Ureter & 150 & 22 & & 0.794 & $0.421-1.500$ & & 25 & & - & - & - \\
\hline & $\begin{array}{l}\text { Renal pelvis \& } \\
\text { ureter }\end{array}$ & 49 & 15 & & 1.641 & $0.452-5.955$ & & 14 & & - & - & \\
\hline \multirow[t]{2}{*}{ Multifocality } & Single & 273 & 48 & $0.0042^{*}$ & 1 & - & $0.006^{*}$ & 52 & $0.0196^{*}$ & 1 & - & $0.002^{*}$ \\
\hline & Multifocal & 62 & 18 & & 2.809 & $1.355-6.162$ & & 18 & & 2.383 & $1.369-4.149$ & \\
\hline \multirow[t]{3}{*}{ Primary tumor $(\mathrm{T})$} & $\mathrm{Ta}$ & 89 & 2 & $<0.0001^{*}$ & 1 & - & $0.010^{*}$ & 4 & $<0.0001^{*}$ & 1 & - & 0.106 \\
\hline & $\mathrm{T} 1$ & 92 & 9 & & 1.832 & $0.976-4.202$ & & 15 & & 2.641 & $0.844-8.264$ & \\
\hline & $\mathrm{T} 2-\mathrm{T} 4$ & 159 & 50 & & 6.173 & $1.359-27.78$ & & 51 & & 2.867 & $0.905-9.082$ & \\
\hline \multirow[t]{2}{*}{ Nodal metastasis } & Negative (N0) & 312 & 42 & $<0.0001^{*}$ & 1 & - & $<0.001^{*}$ & 55 & $<0.0001^{*}$ & 1 & - & $0.001^{*}$ \\
\hline & Positive (N1-N2) & 28 & 19 & & 4.971 & $2.657-9.301$ & & 15 & & 2.932 & $1.575-5.457$ & \\
\hline \multirow[t]{2}{*}{ Histological grade } & Low grade & 56 & 4 & $0.0171^{*}$ & 1 & - & $0.044^{*}$ & 3 & $0.0019^{*}$ & 1 & - & 0.058 \\
\hline & High grade & 284 & 57 & & 3.182 & $1.034-9.788$ & & 67 & & 3.288 & $0.961-11.249$ & \\
\hline \multirow[t]{2}{*}{ Vascular invasion } & Absent & 234 & 24 & $<0.0001^{*}$ & 1 & - & 0.351 & 26 & $<0.0001^{*}$ & 1 & - & $0.015^{*}$ \\
\hline & Present & 106 & 37 & & 1.337 & $0.726-2.463$ & & 44 & & 2.184 & $1.162-4.105$ & \\
\hline \multirow[t]{2}{*}{ Perineural invasion } & Absent & 321 & 50 & $<0.0001^{*}$ & 1 & - & $0.002^{*}$ & 61 & $<0.0001^{*}$ & 1 & - & $0.018^{*}$ \\
\hline & Present & 19 & 11 & & 3.335 & $1.556-7.150$ & -- & 9 & & 2.485 & $1.172-5.210$ & \\
\hline \multirow{2}{*}{$\begin{array}{l}\text { Mitotic rate (per } 10 \\
\text { high power fields) }\end{array}$} & $<10$ & 173 & 27 & 0.1268 & - & - & - & 30 & 0.0581 & - & - & - \\
\hline & $>=10$ & 167 & 34 & & - & - & - & 40 & & - & - & - \\
\hline \multirow[t]{2}{*}{ SPOCK1 expression } & Low & 170 & 10 & $<0.0001^{*}$ & 1 & - & $0.031^{*}$ & 14 & $<0.0001^{*}$ & 1 & - & $0.039^{*}$ \\
\hline & High & 170 & 50 & & 2.278 & $1.080-4.803$ & & 56 & & 2.016 & $1.037-3.916$ & \\
\hline
\end{tabular}

* Statistically significant 
Table 4. Univariate log-rank and multivariate analyses for Disease-specific and Metastasis-free Survivals in urinary bladder urothelial carcinoma.

\begin{tabular}{|c|c|c|c|c|c|c|c|c|c|c|c|c|}
\hline \multirow[t]{3}{*}{ Parameter } & \multirow[t]{3}{*}{ Category } & \multirow{3}{*}{$\begin{array}{l}\text { Case } \\
\text { No. }\end{array}$} & \multicolumn{5}{|c|}{ Disease-specific Survival } & \multicolumn{5}{|c|}{ Metastasis-free Survival } \\
\hline & & & \multicolumn{2}{|c|}{ Univariate analysis } & \multicolumn{2}{|c|}{ Multivariate analysis } & \multirow[b]{2}{*}{$P$ value } & \multicolumn{2}{|c|}{ Univariate analysis } & \multicolumn{3}{|c|}{ Multivariate analysis } \\
\hline & & & $\begin{array}{l}\text { No. of } \\
\text { event }\end{array}$ & $P$ value & R.R. & 95\% C.I. & & $\begin{array}{l}\text { No. of } \\
\text { event }\end{array}$ & $P$ value & R.R. & 95\% C.I. & $P$ value \\
\hline \multirow[t]{2}{*}{ Gender } & Male & 216 & 41 & 0.4906 & - & - & - & 61 & 0.2745 & - & - & - \\
\hline & Female & 79 & 11 & & - & - & - & 16 & & - & - & - \\
\hline \multirow[t]{2}{*}{ Age (years) } & $<65$ & 121 & 17 & 0.1315 & - & - & - & 32 & 0.8786 & - & - & - \\
\hline & $\geq 65$ & 174 & 35 & & - & - & - & 45 & & & & \\
\hline \multirow{3}{*}{$\begin{array}{l}\text { Primary } \\
\text { tumor }(\mathrm{T})\end{array}$} & $\mathrm{Ta}$ & 84 & 1 & $<0.0001^{*}$ & 1 & - & $<0.001^{*}$ & 4 & $<0.0001^{*}$ & 1 & - & $0.008^{*}$ \\
\hline & $\mathrm{T} 1$ & 88 & 9 & & 2.823 & $0.307-25.968$ & & 23 & & 2.595 & $0.757-8.891$ & \\
\hline & $\mathrm{T} 2-\mathrm{T} 4$ & 123 & 42 & & 12.821 & $1.459-112.681$ & & 50 & & 4.363 & $1.271-14.977$ & \\
\hline \multirow{2}{*}{$\begin{array}{l}\text { Nodal } \\
\text { metastasis }\end{array}$} & Negative (N0) & 266 & 41 & $0.0001^{*}$ & 1 & - & 0.444 & 61 & $<0.0001^{*}$ & 1 & - & $0.009^{*}$ \\
\hline & Positive (N1-N2) & 29 & 11 & & 1.315 & $0.652-2.650$ & & 16 & & 2.216 & $1.217-4.034$ & \\
\hline \multirow{2}{*}{$\begin{array}{l}\text { Histological } \\
\text { grade }\end{array}$} & Low grade & 56 & 2 & $0.0016^{*}$ & 1 & - & 0.899 & 5 & $0.0007^{*}$ & 1 & - & 0.891 \\
\hline & High grade & 239 & 50 & & 1.101 & $0.248-4.880$ & & 72 & & 1.073 & $0.393-2.927$ & \\
\hline \multirow{2}{*}{$\begin{array}{l}\text { Vascular } \\
\text { invasion }\end{array}$} & Absent & 246 & 37 & $0.0010^{*}$ & 1 & - & $0.032^{*}$ & 54 & $<0.0001^{*}$ & 1 & - & 0.600 \\
\hline & Present & 49 & 15 & & 2.096 & $1.064-4.132$ & & 23 & & 1.167 & $0.654-2.083$ & \\
\hline \multirow{2}{*}{$\begin{array}{l}\text { Perineural } \\
\text { invasion }\end{array}$} & Absent & 275 & 44 & $<0.0001^{*}$ & 1 & - & $0.025^{*}$ & 67 & $0.0003^{*}$ & 1 & - & 0.161 \\
\hline & Present & 20 & 8 & & 2.601 & $1.127-6.004$ & & 10 & & 1.696 & $0.810-3.554$ & \\
\hline \multirow{2}{*}{$\begin{array}{l}\text { Mitotic rate } \\
\text { (per } 10 \text { high } \\
\text { power fields) }\end{array}$} & $<10$ & 139 & 12 & $0.0001^{*}$ & 1 & - & $0.015^{*}$ & 23 & $<0.0002^{*}$ & 1 & - & $0.009^{*}$ \\
\hline & $>=10$ & 156 & 40 & & 2.279 & $1.170-4.439$ & & 54 & & 1.958 & $1.181-3.247$ & \\
\hline \multirow{2}{*}{$\begin{array}{l}\text { SPOCK1 } \\
\text { expression }\end{array}$} & Low & 147 & 5 & $<0.0001^{*}$ & 1 & - & $<0.001^{*}$ & 13 & $<0.0001^{*}$ & 1 & - & $<0.001^{*}$ \\
\hline & High & 148 & 47 & & 6.965 & $2.725-17.801$ & & 64 & & 4.675 & $2.515-8.690$ & \\
\hline
\end{tabular}

* Statistically significant
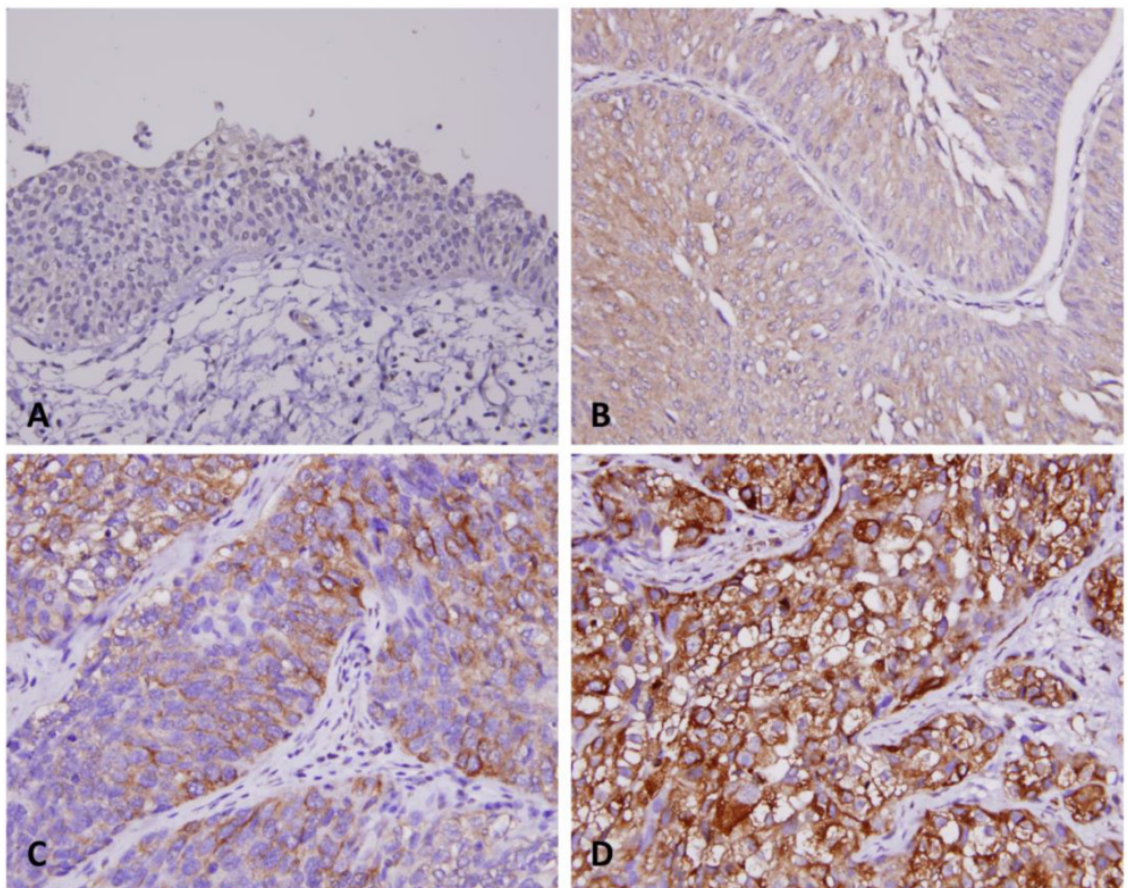

Figure 3. Immunohistochemical staining for SPOCK1 in representative urothelium. Compared with surrounding non-tumorous tissues (A), the tumor tissues have significantly escalated immunostaining for SPOCK 1 from non-invasive (B), superficially invasive (C) and deeply invasive urithelial carcinoma (D). 

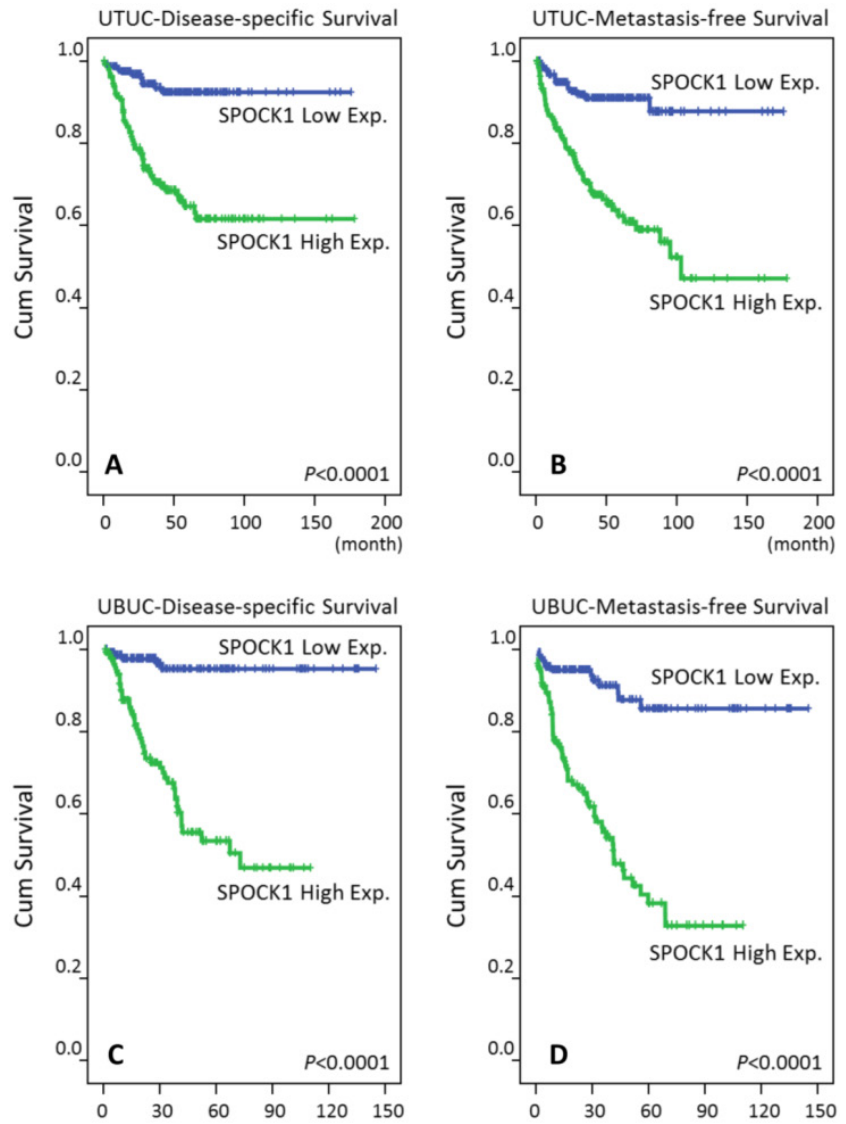

Figure 4. Survival analysis plotted by Kaplan-Meier curves. By log-rank test, high expression of SPOCK1 is predictive for inferior disease-free survival in both UTUC and UBUC $(A, C)$ and for poor metastasis-free survival in both UTUC and UBUC (B, D).

\section{Discussions}

Interesting in markers of UC prognosis, the study identified five significantly expressed genes related to cell motility due to that invasion and metastasis had been suggested associating with adverse outcome in patients with UC. Among those genes, both CALD1 and SPOCK1 were expressed significantly, fitting with a $\log 2$ ratio over 1 and 0.5 fold in primary tumor status and distal metastasis, respectively (Table 1). CALD1 is involved in cell motility through the organization of the actin skeleton and actin/myosin-dependent contractility [14]. SPOCK1, a highly conserved, multidomain proteoglycan in the extracellular matrix, could play a role in modulating protease activity [7]. In the pilot study, only SPOCK1 exhibited crucial differences in primary tumor status, nodal metastasis and survival (Table S1, Table S2), implying its importance in UC aggressiveness compared to CALD1. In Fig. 2, higher pT was related to higher SPOCK1 mRNA expression. In addition, worse DSSs and MeFSs were associated with higher SPOCK1expression (Fig. 4). Aforementioned data may support the probable utility of SPOCK1 as a poor prognostic factor of UC.

SPOCK1, known as testican-1, was originally identified in seminal plasma [15]. The expression of SPOCK1 mRNA in humans has been noted in various tissues with the highest levels in the brain, the prostate, and the testis [16]. A study showed that a de novo missense change in SPOCK1 identified by whole exon sequencing might relate to developmental delay, microcephaly and agenesis of the corpus callosum, leading to the hypothesis that SPOCK1 plays a critical role in neurogenesis [17]. SPOCK1 contains three domains viz., a follistatin domain, an extracellular calcium-binding domain, and a thyroglobulin type-1 domain, which possess functions of regulating metalloproteinase, and cysteine and serine proteases [16, 17]. In a genome-wide association study of age at menarche, SPOCK1 was identified as a novel gene and arousing speculation about the underlying mechanism regarding its influence on matrix metalloproteinase-2 [18].

Furthermore, in the study of gastrointestinal neuroendocrine carcinomas, SPOCK1 was identified by microarray analysis as a candidate related to metastasis and was expressed 100-fold more in tumor material than in normal ileum [19]. Upregulated SPOCK1 has also been identified in lung cancer [20], HCC [10], and gallbladder cancer [21]. The clinical significance of SPOCK1 in lung cancer was correlated with metastasis and silencing of SPOCK1 in cell study inhibited lung cancer cell invasion in vitro [20]. In addition, the tumorigenic ability of SPOCK1 in HCC was investigated in a xenograft mouse model with promising results [10]. In our findings, SPOCK1 was also expressed more strongly in tumor tissues than in normal ones (Fig. 3). Moreover, higher expression of SPOCK1 is also related to positive nodal metastasis and presence of vascular and perineural invasion (Table 2), suggesting that it may have a role in UC invasion and metastasis, as noted with other cancers.

Also, altered composition of the extracellular matrix (ECM) is important in cancer. Epithelial-mesenchymal transition (EMT) involves changes in the cells themselves and in their surrounding microenvironment. Many studies support that obtaining epithelial-mesenchymal transition (EMT) features correlates with poor outcome among patients with various cancer types, including colorectal [22], lung [23], breast [24], and bladder cancer [25]. SPOCK1, the ECM gene, was not only overexpressed in prostate cancer tissues compared to benign samples, but also indicated a tendency toward earlier recurrence [26]. Interestingly, our study showed that high levels of SPOCK1 expression are correlated to poor DSS and MFS in UC in univariate log-rank tests (Table 3, 
Table 4). In vivo studies of lung cancer demonstrated that SPOCK1 is not only associated with metastasis and also induces EMT [20]. Aforementioned facts may suggest that in UC, SPOCK1 may be a novel prognostic factor and may participate in tumor invasion and metastasis through involvement in the process of EMT.

Moreover, evading apoptosis is another capability that characterizes cancer cells [27]. One study of GBC found that SPOCK1 not only promotes cell migration and invasion by inducing EMT but also inhibits apoptosis [21]. The PI3 kinase-ATK/PKB pathway is important in affecting apoptosis [27]. In a mouse model, this signal pathway was demonstrated to have role in upper tract of UC [28]. The PI3 kinase-ATK/PKB pathway is also a downstream kinase pathway triggered by FGFR3, one of the important molecules involving bladder of UC [29]. Furthermore, higher SPOCK1 expression was correlated with higher mitotic rate, as shown in Table-2, indicating that the adverse prognosis associated with high SPOCK1 expression may also relate to cell proliferation.

In conclusion, we present that higher SPOCK1 is related to unfavorable clinicopathological parameters and shorter survival in UC patients. Hypothetically, SPOCK1 may play an important role in the EMT of UC, and may be crucial in UC metastasis. Probably, SPOCK1 may also take a part in evading apoptosis through cell proliferation. This study suggested that SPOCK1 could be an independent prognostic factor in $\mathrm{UC}$, might serve as an oncogene and would be a candidate of target therapy.

\section{Supplementary Material}

Tables S1-S2.

http://www.jcancer.org/v07p0467s1.pdf

\section{Abbreviations}

DSS: disease-specific survival; MeFS: metastasis-free survival; SPOCK1: sparc/osteonectin, cwCV and kazal-like domains proteoglycan (testican) 1; UBUC: urinary bladder urothelial carcinoma; UC: urothelial carcinoma; UTUC: upper tract urothelial carcinoma.

\section{Acknowledgments}

This study was supported by Chi Mei Medical Center (CMFHR10303), Ministry of Health and Welfare (MOHW103-TD-B-111-05) and E-Da Hospital (EDAHP104022). The authors are grateful to the BioBank of Chi Mei Medical Center to provide the tumor samples.

\section{Ethical standard}

This study was approved by the Institutional Review Board (IRB) of Chi Mei Medical Center, approval number IRB10302015. All samples were obtained from the BioBank of Chi Mei Medical Center and had been previously collected following official ethical guidelines. Informed consent has been obtained for those enrolled into BioBank.

\section{Conflict of interest}

The authors declare that they have no conflict of interest.

\section{References}

1. Liao AC, $\mathrm{Li} \mathrm{CF}$, Shen $\mathrm{KH}$, et al. Loss of lactate dehydrogenase B subunit expression is correlated with tumour progression and independently predicts inferior disease-specific survival in urinary bladder urothelial carcinoma. Pathology 2011; 43(7): 707-712.

2. Liang PI, Li WM, Wang $\mathrm{YH}$, et al. HuR cytoplasmic expression is associated with increased cyclin A expression and poor outcome with upper urinary tract urothelial carcinoma. BMC Cancer 2012; 12: 611. doi: 10.1186/1471-2407-12-611.

3. Cheng L, Zhang S, MacLennan GT, et al. Bladder cancer: translating molecular genetic insights into clinical practice. Hum Pathol 2011; 42(4): 455-481. doi: 10.1016/j.humpath.2010.07.007.

4. Cheng L, Lopez-Beltran A, MacLennan GT, et al. Neoplasms of the urinary bladder. In: Urologic surgical pathology, $2^{\text {nd }}$ ed. Philadelphia: Elsevier/Mosby; 2008: 259-352.

5. Fujita K, Uemura M, Yamamoto $\mathrm{Y}$, et al. Preoperative risk stratification for cancer-specific survival of patients with upper urinary tract urothelial carcinoma treated by nephroureterectomy. Int J Clin Oncol 2015; 20(1): 156-163. doi: 10.1007/s10147-014-0695-1.

6. [Internet] UpToDate: Joaquim Bellmunt. Treatment of metastatic urothelial cancer of the bladder and urinary tract. This topic last updated: June 26, 2015. http://www.uptodate.com/contents/treatment-of-metastatic-urothelial-canc er-of-the-bladder-and-urinary-tract?source=search_result\&search=treatment+ of + metastatic+urothelial\&selectedTitle $=1 \% 7 \mathrm{E} 150$

7. Bradshaw AD. Diverse biological functions of the SPARC family of proteins. Int J Biochem Cell Biol 2012; 44(3): 480-488. doi: 10.1016/j.biocel.2011.12.021.

8. Tai IT, Tang MJ. SPARC in cancer biology: its role in cancer progression and potential for therapy. Drug Resist Update 2008; 11(6): 231-246. doi: 10.1016/j.drup.2008.08.005

9. Colin C, Baeza N, Bartoli C, et al. Identification of genes differentially expressed in glioblastoma versus pilocytic astrocytoma using suppression subtractive hybridization. Oncogene 2006; 25(19): 2818-2826.

10. $\mathrm{Li}$ Y, Chen $\mathrm{L}, \mathrm{Chan} \mathrm{TH}$, et al. SPOCK1 is regulated by CHD1L and blocks apoptosis and promotes HCC cell invasiveness and metastasis in mice. Gastroenterology 2013; 144(1): 179-191. e4. doi: 10.1053/j.gastro.2012.09.042.

11. Liang PI, Wang YH, Wu TF, et al. IGFBP-5 overexpression as a poor prognostic factor in patients with urothelial carcinomas of upper urinary tracts and urinary bladder. J Clin Pathol 2013; 66(7): 573-582. doi: 10.1136/jclinpath-2012-201278.

12. Budwit-Novotny DA, McCarty KS, Cox EB, et al. Immunohistochemical analyses of estrogen receptor in endometrial adenocarcinoma using a monoclonal antibody. Cancer Res 1986; 46(10): 5419-5425.

13. McClelland RA, Finlay P, Walker KJ, et al. Automated quantitation of immunocytochemically localized estrogen receptors in human breast cancer. Cancer Res 1990; 50(12): 3545-3550.

14. Mayanagi T, Sobue K. Diversification of caldesmon-linked actin cytoskeleton in cell motility. Cell Adh Migr 2011; 5(2): 150-159.

15. Alliel PM, Perin JP, Jollès P, et al. Testican, a multidomain testicular proteoglycan resembling modulators of cell social behaviour. Eur J Biochem 1993; 214(1): 347-350.

16. Edgell CJ, BaSalamah MA, Marr HS. Testican-1: a differentially expressed proteoglycan with protease inhibiting activities. Int Rev Cytol 2004; 236: 101-122.

17. Dhamija R, Graham JM Jr, Smaoui N, et al. Novel de novo SPOCK1 mutation in a proband with developmental delay, microcephaly and agenesis of corpus callosum. Eur J Med Genet 2014; 57(4): 181-184. doi: 10.1016/j.ejmg.2014.02.009.

18. Liu YZ, Guo YF, Wang L, et al. Genome-wide association analyses identify SPOCK as a key novel gene underlying age at menarche. PLoS Genet 2009; 5(3): e1000420. doi: 10.1371/journal.pgen.1000420.

19. Leja J, Essaghir A, Essand M, et al. Novel markers for enterochromaffin cells and gastrointestinal neuroendocrine carcinomas. Mod Pathol 2009; 22(2): 261-272. doi: 10.1038/modpathol.2008.174. 
20. Miao L, Wang $\mathrm{Y}$, Xia H, et al. SPOCK1 is a novel transforming growth factor- $\beta$ target gene that regulates lung cancer cell epithelial-mesenchymal transition. Biochem Biophys Res Commun 2013; 440(4):792-797. doi: 10.1016/j.bbrc.2013.10.024.

21. Shu YJ, Weng H, Ye YY, et al. SPOCK1 as a potential cancer prognostic marker promotes the proliferation and metastasis of gallbladder cancer cells by activating the PI3K/AKT pathway. Mol Cancer 2015; 14: 12. doi: 10.1186/s12943-014-0276-y.

22. Shan ZZ, Yan XB, Yan LL, et al. Overexpression of Tbx3 is correlated with epithelial-mesenchymal transition phenotype and predicts poor prognosis of colorectal cancer. Am J Cancer Res 2014; 5(1): 344-353.

23. Chen X, Guan X, Zhang H, et al. DAL-1 attenuates epithelial to mesenchymal transition in lung cancer. J Exp Clin Cancer Res 2015; 34: 3. doi: 10.1186/s13046-014-0117-2.

24. Ribeiro AS and Paredes J. P-Cadherin linking breast cancer stem cells and invasion: a promising marker to identify an "intermediates/metastable" EMT state. Front Oncol 2015; 4: 371. doi: 10.3389/fonc.2014.00371.

25. Adam L, Zhong M, Choi W, et al. miR-200 expression regulates epithelial-to-mesenchymal transition in bladder cancer cells and reverses resistance to epidermal growth factor receptor therapy. Clin Cancer Res 2009; 15(16):5060-5072.

26. Wlazlinski A, Engers R, Hoffmann MJ, et al. Downregulation of several fibulin genes in prostate cancer. Prostate 2007; 67(16): 1770-1780.

27. Hanahan D, Weinberg RA. The hallmarks of cancer. Cell 2000; 100(1): 57-70.

28. Qian CN, Furge KA, Knol J, et al. Activation of the PI3K/AKT pathway induces urothelial carcinoma of the renal pelvis: identification in human tumors and confirmation in animal models. Cancer Res 2009; 69(21): 8256-8264. doi: 10.1158/0008-5472.CAN-09-1689.

29. Cheng L, Zhang S, MacLennan GT, et al. Bladder cancer: translating molecular genetic insights into clinical practice. Hum Pathol 2011; 42(4):455-481. doi: 10.1016/j.humpath.2010.07.007 